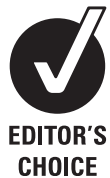

1 Department of Research, Finnmark Hospital Trust, Hammerfest, Norway

${ }^{2}$ Institute of Clinical Medicine, University of Oslo, Oslo, Norway ${ }^{3} \mathrm{H} \emptyset \mathrm{KH}$, Research Centre, Akershus University Hospital, Norway

${ }^{4}$ Centre for Medical Ethics, University of Oslo, Oslo, Norway ${ }^{5}$ Department of Community Medicine, Faculty of Health Sciences, University of Tromsø, Tromsø, Norway

\section{Correspondence to}

Kari Milch Agledahl, Department of Research, Finnmark Hospital

Trust, Hammerfest 9616, Norway; kari.agledahl@ helse-finnmark.no

Received 18 December 2010 Revised 11 April 2011 Accepted 14 April 2011 Published Online First 24 May 2011

\section{(2) UNLOCKA}

This paper is freely available online under the BMJ Journals unlocked scheme, see http:// jme.bmj.com/site/about/ unlocked.xhtml

\title{
Courteous but not curious: how doctors' politeness masks their existential neglect. A qualitative study of video-recorded patient consultations
}

\author{
Kari Milch Agledahl, ${ }^{1}$ Pål Gulbrandsen, ${ }^{2,3}$ Reidun Førde, ${ }^{4}$ Åge Wifstad ${ }^{5}$
}

\begin{abstract}
Objective To study how doctors care for their patients, both medically and as fellow humans, through observing their conduct in patient-doctor encounters.

Design Qualitative study in which 101 videotaped consultations were observed and analysed using a Grounded Theory approach, generating explanatory categories through a hermeneutical analysis of the taped consultations.
\end{abstract}

Setting A 500-bed general teaching hospital in Norway. Participants 71 doctors working in clinical non-psychiatric departments and their patients.

Results The doctors were concerned about their patients' health and how their medical knowledge could be of service. This medical focus often over-rode other important aspects of the consultations, especially existential elements. The doctors actively directed the focus away from their patients' existential concerns onto medical facts and rarely addressed the personal aspects of a patient's condition, treating them in a biomechanical manner. At the same time, however, the doctors attended to their patients with courteousness, displaying a polite and friendly attitude and emphasising the relationship between them.

Conclusions The study suggests that the main failing of patient-doctor encounters is not a lack of courteous manners, but the moral offence patients experience when existential concerns are ignored. Improving doctors' social and communication skills cannot resolve this moral problem, which appears to be intrinsically bound to modern medical practice. Acknowledging this moral offence would, however, be the first step towards minimising the effects thereof.

\section{INTRODUCTION}

Caring for patients is a deep-rooted moral obligation in medicine, but what this means is unclear. Several empirical studies have shown that doctors rarely involve their patients in the clinical decisions made about them. ${ }^{1-4}$ Other research has highlighted how doctors focus on the technical and biomedical aspects of a case, and play down patients' own values and feelings. 5 In 2007-8, using observations and interviews, we studied how doctors handle the moral dimensions of their medical work. 7 We found that doctors' medical practice reflected the moral responsibility to improve patients' health, while the personal and human dimensions of patients' suffering were systematically left out. The account of "the good doctor" usually also implies practical human understanding and empathy and has deep roots in our culture, which shapes both patient expectations and doctors' self-understanding. ${ }^{8} 9$ Patients and many doctors have welcomed the development of a more humanistic approach as a reaction to impersonal and scientific modern medicine. ${ }^{10} 11 \mathrm{~A}$ renewed focus on the patient perspective and on how disease affects people's lives has led to movements such as patient-centred medicine and shared decision-making, ${ }^{12-14}$ while also meaning that issues of ethics and communication, previously informal elements of a medical education, now are mandatory parts of the curricula in most Western medical schools. ${ }^{15}$

While a focus on patient autonomy and better communication has probably improved clinical encounters, it does not seem to have resolved the issue of professional caring. Lack of respect and empathy are among the most common complaints made by patients. ${ }^{16} 17$ The ongoing nature of these problems suggests that they are not just isolated cases of malpractice. They might indicate a systematic problem in medical care; however, we still have a long way to go to understand the dimensions of professional care involved in the patient-doctor relationship.

To consider this issue, we designed a new qualitative study using videotaped, routine consultations in a hospital. Our aim was to study how the doctors' care for their patients was reflected in their conduct in order to shed light on what is involved in caring professionally for patients.

\section{MATERIALS AND METHODS}

We conducted a qualitative study on a representative sample of 380 videotaped encounters in a 500bed general teaching hospital in Norway, which was a secondary analysis of an intervention study in 2007-8. ${ }^{18}$ The 71 doctors included in the study were randomly drawn from the population of doctors working in clinical non-psychiatric departments, and the encounters are a convenience-based sample of outpatient consultations, admittance and discharge consultations, ward rounds and consultations involving diagnostic procedures. The encounters were taped before, during and after the doctors had attended a course in clinical communication, and we excluded the recordings made after the intervention. We also excluded the minority of recordings that lasted more than 20 min because many of the longer consultations contained long periods of examination that were not visible on the tape and so were difficult to study.

The study group was constituted to include the broad expertise relevant to the research, with 
a junior doctor and philosopher (KMA), a professor of philosophy ( $\mathrm{\cap W})$, an experienced general practitioner and professor of medical ethics (RF), and an experienced general practitioner and professor of health services research with expertise in clinical communication (PG). The first author watched randomly selected tapes from our subset and took notes on each encounter, focusing particularly on the doctors' behaviour. The data were analysed for the purpose of generating explanatory categories in line with a Grounded Theory approach, and switching between periods of data observation and analysis was conducted hermeneutically to keep the theoretical concepts close to the data. ${ }^{19} 20$ The theory was developed in collaboration with $\AA$ W, while RF and PG went through the data samples independently. After going through 101 encounters, new encounters did not disclose any significant new information, and saturation was achieved. In line with the methodology, KMA selected a subset of 12 encounters that each represented a main category in the emerging theory. All of the authors viewed the selected encounters together and agreed upon their interpretation. Of these, three typical consultations were selected, which illustrated the three main categories presented below particularly well. All authors agreed upon the final case descriptions and read and revised the manuscript.

\section{RESULTS}

We found that the doctors' involvement with their patients could be classified according to three different dimensions: medical concern, courteousness and existential care.

The doctors' medical concerns were mainly directed at how patients' health was impaired and how their medical knowledge could help. This was evident from how they followed up patients' complaints and how their time was prioritised and could be seen as part of the core contract between doctor and patient. Their strong sense of medical concern often caused the doctors to treat their patients as medical objects. Nevertheless, most related to their patients as more than mere objects, but the doctors interacted with their patients as human beings in a trivial manner. We have used the term courteousness to describe how the doctors often displayed a friendly attitude, kept a good tone and emphasised the social relationship with patients. By courteousness we refer to a display of general respect for the patient as a fellow human being, but it is not to be taken as any deeper concern for the life of the patient. On the contrary, the doctors showed little curiosity about the individual and neglected more personal aspects of the patients' conditions, showing little or no existential care. The patients frequently spoke of their personal feelings-for example, describing how they had experienced the current event and how it had affected their lives, but this was rarely addressed or pursued by the doctors, who instead directed the focus away from personal meanings onto medical facts.

These three dimensions of doctors' involvement emerged as a result of the analysis of the entire material; the cases presented below are observed encounters that are selected simply as illustrations of these dimensions.

\section{Case I: visiting the pulmonary specialist}

The doctor greets the patient, a middle-aged man, inviting him to sit. He says he now has recovered from what was probably just an infection. The doctor turns to the computer, nodding occasionally while attending to the screen. The patient suddenly speaks up: "I have really been physically healthy all my life, right until my wife died three... three years ago. Three years ago." The doctor looks at her computer, showing no reaction: "Yes." Patient: "And... and then a great deal seemed to happen... and so the last three years there has been a lot concerning my heart and so, but... otherwise... I guess I am... relatively..." The doctor: "...But otherwise you have been healthy, yes?" Patient: "Yes..." The doctor pulls her chair over to the patient and smiles: "Then there is the big question that is asked of everyone who comes here: Do you smoke?"

The doctor says she has some extra time and enthusiastically draws a curve explaining the effects of smoking on lung function. The patient tells her that he was healthy until his wife's death, and the doctor commends his healthy look. Suddenly she asks if he has any symptoms, which is denied. She says this makes him difficult to diagnose and they both laugh. Referring to the computer system requiring a diagnosis she enters 'COPD'. The patient says another doctor suggested asthma: "...my son has asthma, but it...was also what my wife died from, and... And asthma runs in the family." The doctor stares at the screen, nods and states that further follow-ups are unnecessary. The patient says that he agrees, but goes on to raise additional concerns. The doctor quickly raises her head: "Is there anything else you would like to ask?" "No!" he vigorously declares and rises to leave. The doctor leads him out and wishes him well.

The doctor's first concern is to define the medical problem, and she focuses more on the computer than on the patient. She relies on medical facts from the records, which are read out loud. The doctor overlooks the patient's own accounts of his life and he is declared healthy on the basis of a test result.

When the patient plucks up the courage to mention that his wife has died, the doctor ignores it. Instead of addressing this existential aspect, she quickly changes the subject with a medically focused question about smoking. The next time the subject is brought up, the doctor comments on the patient's physical condition instead. The patient mentions his deceased wife three times, finally revealing that she died of asthma, but any potential anxieties related to his own lung condition are not touched upon. The doctor explicitly states that she has plenty of time, but even so the clearly existential dimensions of the patient's suffering are avoided.

Nevertheless, they speak in a jovial manner. The doctor politely stands up to greet the patient and invites him to sit. She does not rush the consultation, answers the patient's questions about lung function and exercise and takes time to explain matters in detail. Smiling and laughing, she appears to value the social contact. An ambiguous element to the expressed courteousness is revealed, however, when the doctor's otherwise polite request for questions actually serves to interrupt the patient and bring an end to the consultation; a sign the patient seems to sense.

\section{Case II: the anaesthesiologist's round}

An elderly woman sits in bed, glancing regularly at the door. "Mrs Peterson, is that you?" The doctor smiles, introduces himself as an anaesthesiologist and gets a chair. The patient asks whether he is going to carry out the sedation or the operation, but the doctor says no to both. In a friendly voice, he asks brief questions about her medical history, completing an anaesthesia form. The patient answers carefully. She is upset that her daughter had to take care of her because her current leg pain was not taken seriously. The doctor looks down, answering "yes" and "I see". The woman's phone rings and he waits for her to finish.

When the doctor starts to tell the patient about the epidural procedure, she looks uneasy. She asks repeatedly about medication and the possibility of a general anaesthetic. In a friendly voice, but hastily, the doctor explains the advantages of an epidural and proposes tranquillisers. The patient says she already has "such tiny, 
tiny little candies that do no good", and they both laugh heartily. After gathering himself, the doctor asks if she has any questions. She looks serious: "Oh, I wonder about many things." Doctor: "Yes, but to do with the sedation?" Patient: "Only that and not the surgery?" Doctor: "No. Only that."

\begin{abstract}
The patient looks anxious and asks about pain and if she will be awake during the surgery. The doctor reassures her in a friendly voice, but in a quick and impatient manner, and looks at the records: "Okay?" She hesitates: "Okay..? I'm nervous. Terribly nervous. I am." He promises her tranquillisers and repeats: "Okay?" She expresses insecurity about the surgeon and says the anaesthesiologist should be present. He laughs and stands: "Yes, I should. But I am unfortunately doing something else tomorrow." He shakes her hand, wishes her good luck and leaves. The patient looks out the window. She sighs heavily.
\end{abstract}

The patient looks anxious from the beginning, and the doctor approaches her in a friendly and trustworthy way. He takes time to sit down, addresses her directly, looks straight at her and maintains reciprocal contact, demonstrating his courteousness. Seemingly encouraged, the patient eagerly answers his questions and shares her personal frustrations. After establishing this social contact, the doctor maintains a medical focus, framing his questions to deal with the anaesthesia form, taking no notice of the patient's account of her distressing and humiliating experiences. When he has completed his medical tasks, he tries to end the consultation by almost compelling the patient to agree that everything is now "okay", displaying again his delimited medical concern.

The doctor's courteousness seems to be important to the patient, both as he patiently waits while she answers her phone and when they both start laughing. And yet, at this very moment, the doctor explicitly delimits his relationship with her and returns to his medical tasks. Although the doctor's medical responsibilities may be limited to the anaesthetic procedure, existential care cannot be delimited as easily. Both the patient's manner and her repeated questions about pain reveal her anxiety about the surgery. An attempt to deal only with the component of her fear that relates to an epidural procedure demonstrates an avoidance of her existential needs and is also ineffective. Only allowed to ask about the anaesthesia, the patient tries to frame her questions in terms of sedation, and ultimately states in general terms that she is 'terribly nervous'. But the doctor never addresses the existential dimension of this fear and proposes the medical solution: more sedatives.

\section{Case III: a cancer follow-up visit}

A 60-year-old man enters with his wife. Diagnosed with metastasising cancer a year ago, he has undergone an operation and seven subsequent chemotherapy sessions. The doctor looks forthcoming and attentive and presents the medical history while glancing at the patient for confirmation. From the computer he identifies the current issue as the growth of one of the metastases. The patient explains that he can feel the tumour growing and the doctor asks about symptoms like urination problems, pain and nutrition. The patient describes a gradual loss of appetite, which his wife confirms. Looking at the computer, the doctor nods. "Yes. Yes, I can see that... Yes, I can tell from your blood results that you... you are in what we call a catabolic state, which means that you break down a little more than you build up." When the wife expresses concern about her husband's weariness, the doctor attempts to quantify his daily activities. Afterwards, he examines the patient's stomach and exclaims: "Yes! But this we can... We can manage to radiate this one, I'm sure."

Left alone for a moment, the patient and his wife express anxiety at the rapid progress of the disease. In a timid voice, the wife questions the treatment when the doctor re-enters the room, and he briefly explains why radiation is the preferred treatment, going into details about the radiation procedure while the patient listens and nods. He sums up the plan, but the patient makes no move to leave. The wife brings up the liver metastasis, but the doctor dismisses her. The patient nods: "Right, right. Yes, yes.", but he does not move. After a moment of silence, the patient finally rises: "Well, well... But then... I guess it sounds okay then." The doctor smiles, says "see you later" and shakes their hands.

Again, the doctor's strong medical concerns guided the conversation, overshadowing other important matters. Even though all the treatment is palliative, the patient's underlying existential agony is never addressed, and is even actively disregarded. The doctor focuses on the medical data and only allows the patient to comment on this. The computer, rather than the patient, is asked about the reason for the consultation, which is defined as 'growth of one of the metastases'.

The doctor avoids obvious existential concerns; when the patient talks about the tumour, the doctor does not address the underlying fear but asks about symptoms. Likewise, when the patient's increasing tiredness is brought up, he is made to quantify his activity levels. Explicit worries are met with medical answers, and the patient's dying process is even described as 'a catabolic condition'. The tacit existential dimension appears uncomfortably present at the end, when the fears that are unaddressed seem to prevent the patient from leaving.

But the doctor also shows courteousness, and is attentive to both the patient and his wife, maintaining a good atmosphere and often smiling. He is polite, listens patiently, takes time to answer questions and does not hurry the patient out. Still, the light tone and the almost cheerful doctor make a stark contrast to the patient's grave situation. These contrasts are highlighted at the end of the consultation when the doctor says he will see them later, when they are probably all aware that there might be no "later" for this patient.

\section{DISCUSSION}

The study confirms our earlier findings: the doctors' main focus was on medical problems, which overshadowed other aspects of the consultations, most notably the existential dimensions. ${ }^{17}$ Personal meanings of the patients' conditions were systematically omitted or overlooked. Others have described doctors' lack of empathetic responses and failure to respond to patients' clues. $^{21-23}$ The regularity of this conduct suggests that it should not be taken as an example of bad medical practice, but as part of the ordinary interactions between doctors and patients - that is, a function of 'medical processing'. ${ }^{24}$ Bioethicists, as well as a major humanist movement in medicine, have called attention to the suffering of the patient, requested personal involvement of the doctor and emphasised the need to address patients as whole human beings with unique lifeworlds. ${ }^{25-27}$ Yet, in order to perform their clinical tasks, doctors must apply their scientific medical knowledge to their patients, which involves some objectification and a certain disregard for personal narratives; a suggestion advanced by medical sociologists decades ago. ${ }^{28}$ If it is inevitable that patients are treated as objects in order to help them medically, this might illuminate why the humanistic medical ideal has been so hard to achieve.

When doctors disregard patients' personal accounts, they risk missing information that is clinically important, making the consultations less medically effective. In the second case, probing the elderly woman's fear of surgery might have lessened her anxiety more than tranquillisers. But what is at stake here is 
more than optimising patients' medical treatment. By ignoring expressed existential matters, doctors disregard their patients' humanity, which is a moral offence that is often perceived negatively. ${ }^{29}$ At the core of the conception of morality and human dignity is the idea that individuals are not reducible to objects, but intrinsically valuable. ${ }^{30}$ While most patients probably allow for this objectification, those with conditions that fundamentally affect their personal lives may be particularly vulnerable.

Although the study confirms doctors' lack of personal curiosity and existential care, it also reveals that they are not insensitive to their patients as individuals. Indeed, the doctors in our study demonstrated a respect for their patients as fellow humans through social contact, polite behaviour and friendliness. Their strong medical focus often led the doctors to neglect personal accounts, but patients were also clearly treated with courteousness. While this ambiguity of professional care was exposed in many of the cases observed, there is little to suggest that the doctors were aware of it. Often, patients were handled in an almost mechanical manner, suggesting that the doctors conceived the circumstances as straightforward and uncomplicated. They shifted readily from talking cheerfully to patients, to reducing them to medical objects by letting the dialogue drift into a physical examination, or looking at the computer while making conversation. The doctors' overt expressions of courteousness might actually conceal the ongoing objectification for both doctor and patient, leading the former to perceive the consultation as straightforward and satisfactory. When personal concerns were overlooked, the doctors' friendliness often seemed to make their patients puzzled and unable to voice any protest.

When it comes to professional caring, the study reveals the importance of distinguishing between doctors' existential care, which they mostly lack, and their courteousness, which they clearly display. Various attempts to foster professionalism among medical students and doctors have demanded empathy, altruism and integrity. ${ }^{31}$ However it is uncertain whether it is possible for doctors to care for patients existentially while also attending to their clinical responsibilities which requires them to apply a depersonalised medical science. Courteousness may improve the doctor-patient relationship, but the moral offence of being handled like a medical object cannot simply be undone by a friendly and polite doctor. Doctors should be familiar with the negative effects of their professional care even if they are unavoidable. When doctors are unable to follow-up on a patient's personal perspective, they should be aware of the moral harm caused by this rejection. They should seek to minimise it by attending to his/her humanity as far as possible within the medical setting, and apologise when unable to address personal issues. Courteousness can thus have moral significance if expressed, not to conceal an ongoing medical objectification, but to recognise the patients' humanity, which is always threatened in a professional doctor-patient relationship.

Our qualitative findings cannot be generalised in the same way as quantitative results. ${ }^{32}$ The consultations were taped at one Norwegian hospital, and care should be taken in applying our findings to other fields. Medical practice in Norway is not fundamentally different from that in other Western countries, suggesting that the results are transferable to similar settings elsewhere. Our findings are also in accordance with similar studies from other countries, as highlighted in this discussion. We had a large sample size and the participant doctors varied in specialty, age and experience. However, only hospital doctors were included, and it is possible that general practitioners attend more to the patients as people. The fact that the doctors knew that they participated in a study of clinical communication probably made them more conscious of their actions, not displaying their worst behaviour. In light of this bias, it is interesting that we still found such a lack of existential care.

Acknowledgements We would like to express our gratitude to the patients and doctors who kindly participated in the study, and to Bård Fossli Jensen, who did a major job in including patients and taping encounters. We would also thank the JME reviewers for helpful and constructive comments.

Funding KMA received funding from Finnmark Hospital Trust (NO) and Northern Norway Regional Health Authority. South-Eastern Norway Regional Health Authority funded the study in which data were collected. The funding sources had no role in the design, data collection, data analysis, data interpretation, writing, or decision to submit the article for publication.

\section{Competing interests None}

Ethics approval This study was conducted with the approval of the REK Sør-Øst C, Postboks 1130, Blindern, 0318 Oslo, Norway (Nr 2009/913). All patients and doctors provided written informed consent.

Contributors PG was responsible for the study in which the videotapes were collected, and collected some of the videotapes. KMA and $\AA W$ developed the theoretical framework and designed the study. KMA analysed and interpreted all data and wrote the first draft of the manuscript. AW, PG and RF participated in the data analysis and interpretation. All authors reviewed and revised drafts of the manuscript and had full access to all data in the study. All authors made a final approval of the version submitted for publication. KMA is the guarantor.

Provenance and peer review Not commissioned; externally peer reviewed.

\section{REFERENCES}

1. Braddock CH 3rd, Edwards KA, Hasenberg NM, et al. Informed decision making in outpatient practice: time to get back to basics. JAMA 1999:282:2313-20.

2. Karnieli-Miller 0, Eisikovits Z. Physician as partner or salesman? Shared decisionmaking in real-time encounters. Soc Sci Med 2009;69:1-8.

3. Ford $\mathbf{S}$, Schofield T, Hope T. Observing decision-making in the general practice consultation: who makes which decisions? Health Expect 2006:9:130-7.

4. Rogg L, Aasland OG, Graugaard PK, et al. Direct communication, the unquestionable ideal? Oncologists' accounts of communication of bleak prognoses. Psychooncology 2010;19:1221-8

5. Corke CF, Stow PJ, Green DT, et al. How doctors discuss major interventions with high risk patients: an observational study. BMJ 2005:330:182.

6. Hall JA, Dornan MC. What patients like about their medical care and how often they are asked: a meta-analysis of the satisfaction literature. Soc Sci Med 1988:27:935-9.

7. Agledahl KM, Førde R, Wifstad $\AA$. Clinical essentialising: a qualitative study of doctors' medical and moral practice. Med Health Care Philos 2010;13:107-13.

8. Brian Hurwitz, Alex Vass. What's a good doctor and how do you make one? BMJ 2002;325:667.

9. Miles SH. Hippocrates and informed consent. Lancet 2009;374:1322-3.

10. Halperin EC. Preserving the humanities in medical education. Med Teach 2010:32:76-9.

11. Frankel RM, Quill TE, McDaniel SH. The Biopsychosocial Approach: Past, Present Future. New York: University of Rochester Press, 2003.

12. Emanuel EJ, Emanuel LL. Four models of the physician-patient relationship. JAMA 1992;267:2221-6

13. Sandman L, Munthe C. Shared decision making, paternalism and patient choice. Health Care Anal 2010;18:60-84.

14. Epstein RM, Peters E. Beyond information: exploring patients' preferences. JAMA 2009;302:195-7

15. Boudreau JD, Cassell EJ, Fuks A. A healing curriculum. Med Educ 2007;:41:1193-201

16. Meruelo NC. Mediation and medical malpractice: the need to understand why patients sue and a proposal for a specific model of mediation. J Leg Med 2008;29:285-306.

17. Levinson W, Roter DL, Mullooly JP, et al. Physician-patient communication. The relationship with malpractice claims among primary care physicians and surgeons. JAMA 1997;277:553-9.

18. Fossli Jensen B, Gulbrandsen P, Dahl FA et al. Effectiveness of a short course in clinical communication skills for hospital physicians: result of a crossover randomized controlled trial (ISRCTN22153332). Patient Educ Couns. Published Online First: 1 Nov 2010. doi:10.1016/j.pec.2010.08.028.

19. Glaser BG, Strauss F. The Discovery of Grounded Theory: Strategies for Qualitative Research. New York: Aldine de Gruyter, 1967.

20. Glaser BG. Theoretical Sensitivity: Advances in the Methodology of Grounded Theory. California: Sociology Press, 1978.

21. Weiner SJ, Schwartz A, Weaver F, et al. Contextual errors and failures in individualizing patient care. a multicenter study. Ann Intern Med 2010;153:69-75 
22. Suchman AL, Markakis K, Beckman HB, et al. A model of empathic communication in the medical interview. JAMA 1997;277:678-82.

23. Levinson W, Gorawara-Bhat R, Lamb J. A study of patient clues and physician responses in primary care and surgical settings. JAMA 2000;284:1021-7.

24. Macnaughton J. The dangerous practice of empathy. Lancet 2009;373:1940-1.

25. Barry CA, Stenvenson FA, Britten N, et al. Giving voice to the lifeworld. More humane, more effective medical care? A qualitative study of doctor-patient communication in general practice. Soc Sci Med 2001;53:487-505.

26. Cassell EJ. The Nature of Suffering and the Goals of Medicine. New York: Oxford University Press, 1991.
27. Langewitz W. Beyond content analysis and non-verbal behaviour-What about atmosphere? A phenomenological approach. Patient Educ Couns 2007;67:319-23.

28. Parsons T. The Social System. 2nd edn. London: Routledge, 1991.

29. Malterud K. Humiliation instead of care? Lancet 2005:366:785-6.

30. Kant I. Groundwork of the Metaphysics of Morals. New York: Cambridge University Press, 1997.

31. Coulehan J, Williams PC. Conflicting professional values in medical education. Camb 0 Healthc Ethics 2003;12:7-20.

32. Malterud K. Qualitative research: standards, challenges, and guidelines. Lancet 2001:358:483-8.

Advancing Postgraduates. Enhancing Healthcare.

The Postgraduate Medical Journal is dedicated to advancing the understanding of postgraduate medical education and training.

- Acquire the necessary skills to deliver the highest possible standards of patient care

- Develop suitable training programmes for your trainees

- Maintain high standards after training ends

Published on behalf of the fellowship for Postgraduate Medicine
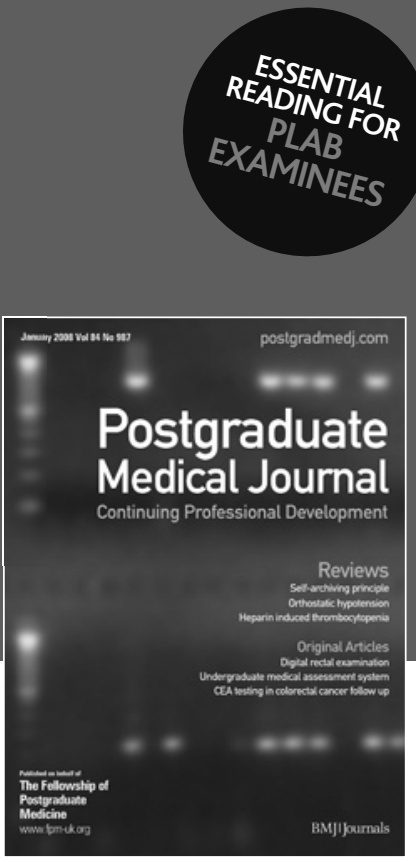

FOR MORE DETAILS OR TO SUBSCRIBE, VISIT THE WEBSITE TODAY

BMJIJournals

\section{postgradmedj.com}

